\title{
ASPECTOS SOCIOCULTURALES DE LA MENSTRUACIÓN EN LA EDAD MEDIA
}

\author{
Gunther Balarezo López
}

\section{Resumen}

Se hizo una revisión bibliográfica de la literatura publicada sobre los aspectos socioculturales de la menstruación en la edad media. Para ello, se analizó diversas publicaciones y se resumió los aspectos más relevantes. La iglesia jugó un papel determinante en la edad media, al tratar de dar explicación a este fenómeno fisiológico en la mujer. Esta explicación relacionaba la menstruación con lo sobrenatural y, por lo tanto, se consideraba a la mujer una intermediaria del diablo. Además, la mujer debía obedecer a lo que dijera la Iglesia sobre este tema, de lo contrario, sería considerada una bruja y estaría viviendo en pecado.

Palabras clave: menstruación, edad media, edad moderna.

\section{Abstract}

A literature review of the published literature on the socio-cultural aspects of menstruation in the middle ages. For this, various publications are analyzed and the most relevant aspects are summarized. The church played a key role in the middle ages, to try to give an explanation for this physiological phenomenon in women. This explanation linked menstruation with the supernatural, and therefore, the woman was considered an intermediary devil. In addition, the woman had to obey what the Church say about this, otherwise it would be considered a witch and would be living in sin.

Keywords: menstruation, middle age. 
La Edad Media, es el período de la historia europea que transcurre desde la desintegración del Imperio Romano en el siglo V (aproximadamente 476) hasta el siglo XV (aproximadamente 1492). En él, a pesar de que el modelo galénico de la medicina sobrevive, es la Iglesia la que juega un papel central, al considerar los trastornos de la salud, sobre todo en la mujer, como producto de la voluntad sobrenatural del diablo. El pecado se constituye en la raíz de todo mal y la confesión es el procedimiento terapéutico para evitarlo. En ese contexto general, predominan dos tendencias sobre el pecado y su resolución: por un lado, está la postura inquisitorial, que anima a identificar y capturar los herejes y brujas para su tratamiento, la cual puede llegar a la tortura y quema; por otro lado, están los que animan a alejarse del pecado de un modo más personal y humanitario.

En tal sentido, con respecto a la menstruación, en la Edad Media se tiene las siguientes creencias: ${ }^{1-17}$

- Se califica la menstruación como un residuo peligroso, que un cuerpo sano tiene que evacuar porque su retención puede producir enfermedades.

- Las autoridades médicas creen que los demonios se producen a partir de la sangre menstrual y hacen referencia a la influencia que ejerce la luna sobre los ciclos menstruales.

- Si el hombre realiza el coito con una mujer menstruante puede enfermar, sobre todo si realiza dicho coito en la posición contraria a la marcada por la naturaleza: la de la mujer arriba.

- La mujer es más vulnerable y débil que el hombre ante las enfermedades, debido a que no es capaz de digerir completamente los alimentos, siendo los restos de esta digestión incompleta lo que se evacua con la menstruación.

- Se cree que si las mujeres menstruantes tocan la carne o la mantequilla, esta ya no es comestible. También se asocia a la mujer menstruante con el basilisco (animal al cual se atribuye la propiedad de matar con la vista).

- El hijo que es engendrado durante la menstruación, nacería con el pelo rojo, con todas las connotaciones peyorativas que se vinculan a ese color.

- La mujer, en el período menstrual, puede transmitir veneno a través de la mirada; para ello, el aire tiene la función de intermediario y de conducto entre los ojos y el ser u objeto.

- En ciertas obras y comedias, se utiliza la sangre menstrual como excusa para mostrar el vicio de la lujuria en las mujeres, quienes aducen dicha astucia para apartar a sus maridos y así quedarse algún tiempo más con sus amantes.

- Teólogos escolásticos (movimiento teológico y filosófico que intenta utilizar la filosofia grecolatina clásica para comprender la revelación religiosa del cristianismo), mencionan que "No se permite a las 
mujeres visitar una iglesia durante su periodo menstrual o después del nacimiento de un niño. Esto es porque la mujer es un animal que menstrua”. Además, las mujeres no deben llevar la comunión a los enfermos y deben permanecer fuera de la iglesia luego de que dejan de menstruar. Finalmente, dicen que las mujeres no pueden tocar los vasos sagrados.

- La mujer es vista como un varón imperfecto, que a causa de su frialdad no puede cocer la materia primera procedente del alimento ingerido, corrompiéndose y dando lugar a vapores infectos o humores corrompidos, que al no eliminarse a su debido tiempo producen el envenenamiento de todo el cuerpo. Este proceso se ve aumentado en las mujeres al poder acumular además un nuevo elemento destructivo e impuro: la menstruación, cuando no se ve regulada por las expulsiones periódicas. La mujer se convierte en un ser acostumbrado a vivir con su propio veneno, que expulsa regularmente, contribuyendo así a su purgación y cura.

- Se considera a la menstruación venenosa, de allí que el cuerpo necesariamente requiera purgarla cada mes.

- Los libros sobre la historia de la naturaleza dan unos poderes destructivos a la sangre menstrual. $\mathrm{Si}$ dicha sangre menstrual es retenida en la matriz, produce una serie de vapores venenosos que ascienden hacia el diafragma, el corazón y finalmente la cabeza, siendo la causa de muchas de las enfermedades casi específicas de la mujer: la histeria y la epilepsia, junto con los sincopes.

- La menstruación es un residuo, que tiene analogías con el semen de los hombres. Por tanto, produce un debilitamiento como en los hombres, si cabe mayor, puesto que expulsan el esperma mensualmente, con lo que no pueden crecer tanto y son mucho más débiles. E1 hecho que se produzcan menstruaciones implica que no puede tener esperma.

- Hay diferencias físicas debido a que la menstruación de la mujer para los hombres, es un signo de debilitamiento que confirma que no tiene esperma y, por lo tanto, eso las caracteriza de una impotencia.

- En casos de ausencia de menstruación en la menopausia, genera el nacimiento de pelos en la barba de las mujeres, y el mito de la mujer barbuda. La barba caracteriza al hombre, que es cálido y seco, frente a la mujer que es fría y húmeda.

- Según tratados médicos, cuando las mujeres llegan a la menopausia no dejan de producir sangre menstrual, sino que simplemente pierden la capacidad de expulsarla. Esa sangre menstrual se acumula en sus vientres y de ella nacen unos vapores venenosos invisibles e inodoros que van ascendiendo por los canales del cuerpo hasta los ojos, por donde finalmente se expulsan. Por eso, no debe permitirse que las 
ancianas miren a los niños pequeños, porque pueden infectarlos con esos vapores venenosos y causarles la muerte.

- Se cree que la menstruación es una inferioridad y pecaminosidad de la mujer, por lo que en otras cosas, durante el periodo, tienen prohibido asistir a ceremonias religiosas.

- La sangre menstrual no solo resulta peligrosa para quienes están en contacto con las mujeres, sino también para ellas mismas, porque la acumulación de esta sustancia en la matriz provoca enfermedades, tales como la suffocatio matricis (sofocación de la matriz), así como infecciones oculares infecciosas.

- Con la Santa Inquisición, la mujer es perseguida porque se relaciona a la doncella menstrual con el diablo. En tal sentido, a los hombres se les tiene prohibido tocar a la menstruante. Se considera a la menstruación como un síntoma de una enfermedad desconocida; por ello, a la mujer se le considera en esos dias como "enferma o mala".

- Entre los mayas (siglos III al XV), se creeque para que las semillas crezcan y dén buenos frutos, el sembrador necesita estar completamente desnudo y debe eyacular sobre las semillas; más tarde, si la planta no da frutos, es regada con sangre menstrual. Esto se debe a que como la mujer procrea hijos, con la menstruación la planta puede fructificar. Además, según el calendario lunar, los mayas relacionan la menstruación con la luna.
- Cesáreo de Arles (470-543), en su sermón XLIV, retoma las posiciones de San Jerónimo: "Si alguno conoce a su mujer cuando está en sus reglas, o no se contiene el día dominical o en otras solemnidades, entonces los niños concebidos nacerán leprosos, epilépticos o quizá demoniacos".

- El Papa Gelasio I (494), menciona que las mujeres menstruantes no pueden servir en el altar.

- El Concilio de Epaon (517) decreta que no se ordenen mujeres diáconos en esa región. La razón es el temor de que las mujeres que menstrúan profanen el altar.

- San Isidoro de Sevilla (560-636), en su Etimologías, menciona: “... Al contacto con esta sangre los frutos no germinan; se agrian los mostos; se marchitan las hierbas; los árboles pierden su fruta; el hierro se ve corroído por el moho; los bronces se vuelven negros. Si los perros comen algo que ha estado en contacto con ello, se vuelven rabiosos. Y el betún asfáltico, que no se disuelve con hierro ni con agua, se desmorona al punto cuando es salpicado por esta sangre. Después de varios dias de menstruación, el semen no es fecundable por falta de sangre menstrual que pueda regarlo...".

San Isidoro hace la relación entre la sangre menstrual y la leche materna: "La sangre utilizada para la nutrición del útero va a las mamas y adquiere la calidad de leche".

- El Sínodo Diocesano de Auxerre (588) decreta que las mujeres 
menstruantes deben cubrirse las manos con una tela "dominical" para poder recibir la comunión.

- El Sinodo de Rouen (650) prohíbe a los sacerdotes poner el cáliz en las manos de las mujeres que están menstruando o permitirles distribuir la comunión a los enfermos.

- El Obispo Timoteo de Alejandría (680) y Teodoro de Canterbury (690) ordenan que las mujeres que menstrúan no puedan recibir la comunión, el bautismo o visitar la iglesia en Pascua.

- El Canon II del Concilio de Trullo (692) prohíbe a las mujeres menstruantes acercarse al altar y comulgar.

- El obispo Teodolfo de Orleans (820) dice: "Las mujeres deben recordar su enfermedad y la inferioridad de su sexo; por tanto, deben tener miedo de tocar cualquier cosa sagrada que está en el ministerio de la Iglesia”.

- Abu Bakr Muhammad ar-Razí (844-926), ilustre médico islámico, famoso en Europa con el nombre de Razés, cree que el feto al nacer arrastra consigo del claustro materno una especie de "pecado original": la "materia morbosa", la cual, a causa del cese de la menstruación durante los nueve meses del embarazo, se habría acumulado en el cuerpo de la madre y que, al igual que la espuma, debe ser apartada del zumo durante su fermentación; así, la sangre debe ser purificada de la "materia morbosa" mediante la eliminación de ésta por la piel del mujer.
- Abu Alí al-Husain Ibn Siná (9801037), llamado Avicena en Occidente, menciona que las aguas que contienen alumbre suprimen la menstruación excesiva, pero hacen que las personas propensas a fiebres, lo sean aún más. También menciona que el agua caliente es beneficiosa para las enfermedades de la mujer, porque evoca la menstruación.

- En el 1012, Avicena en su libro El Canon de la Medicina (también conocido como el Canon de Avicena), se especifica que si la sustancia retenida es sangre menstrual, el peligro es que degenera en locura, puesto que la sangre contiene los cuatro humores, y si se encuentra el humor melancólico en forma abundante se propaga al cerebro y provoca locura.

- Entre los siglos IX y XI, en algunos penitenciales cristianos, se aprecia la pregunta en la confesión a las mujeres sobre la utilización de la sangre menstrual para enamorar al marido.

- La Souda (enciclopedia del siglo X), menciona que el filósofo Heraiskos es tan sensible a la influencia de la menstruación, que sufre de jaquecas si oye hablar a una mujer menstruante.

- La mayoría de los penitenciales prohíbe la entrada de la mujer impura en el templo y las relaciones sexuales durante este período. E1 penitencial de Burchard de Worms del siglo XI dice: “¿Te has unido a tu esposa durante sus reglas? Si lo 
has hecho, harás penitencia diez dias a pan y agua. Si tu mujer ha entrado en la Iglesia después del parto, antes de haber sido purificada su sangre, ella hará penitencia tantos dias como habría debido abstenerse alejada de la Iglesia. Y si has copulado con ella esos días, harás penitencia a pan y agua durante veinte dias".

- En la Escuela de Salerno (siglos XI y XII), el texto que más se centra en las enfermedades de las mujeres De Mulierem Passionibus es el atribuido a Trótula, se menciona que “... el flujo menstrual opera una especie de regulación del temperamento femenino. Mientras que en los hombres el calor dominante se atempera mediante el sudor, en las mujeres la humedad excesiva es purgada por las menstruaciones, que el vulgo llama flores, pues al igual que los árboles no producen frutos sin flores, de la misma manera las mujeres sin flores no pueden concebir...”.

Trótula menciona "estar con la flor" para denominar la menstruación, basándose en la metáfora en que los árboles no producen frutos sin flores y las mujeres no conciben sin menstruación. Cuando la mujer no está embarazada, la menstruación sirve fundamentalmente para expulsar los residuos que no han sido objeto de una posterior cocción, falta de calor o falta de actividad fisica más intensa, como se supone sucede en las hembras de otras especies. Esto lo atribuye a una especie de regulación del temperamento femenino, ayudando a eliminar la humedad excesiva.

La sangre menstrual sirve para alimentar al feto durante el embarazo y el periodo de lactancia: "una vez que el niño ha venido al mundo, toda la sangre menstrual refluye a las mamas por una modificación del sistema circulatorio que fue un enigma para los autores medievales".

Trótula también se ocupa del control de la natalidad, estipulando que el mejor momento para la concepción es el último día de la menstruación.

- Otro integrante de la Escuela de Salerno, Constantino el Africano, en su manual Viaticum menciona sobre la menstruación: "La causa de esta pasión es la abundancia de esperma y su corrupción. Aparece cuando las mujeres no realizan el coito con el hombre: entonces el esperma aumenta, se corrompe $y$ se transforma en un veneno. Las viudas son las que más sufren, sobre todo si han tenido varios hijos. Lo mismo les ocurre a las jóvenes cuando llegan a la pubertad si no tienen relaciones con hombres. En efecto, el esperma se acumula para ser expulsado, al igual que en los hombres, cuando la naturaleza asi lo pide. Cuando la mujer no tiene relaciones con hombres, el esperma se acumula y nace un vapor que sube al diafragma, pues el diafragma y la matriz están unidos, y como el diafragma está unido a las partes superiores y a los instrumentos de la voz, la sofocación aparece”. 
- En los tratados Viaticum de Constantino el Africano, o el texto de Trotula De Mulierem Passionibus, se menciona que el coito es visto como el modo más efectivo para provocar la expulsión de la sangre menstrual acumulada. Pero el coito es solo moralmente lícito cuando se practica dentro del matrimonio. En tal sentido, las viudas y las jóvenes solteras están expuestas a los riesgos provocados por la acumulación de sangre menstrual en la matriz. Por ello, a estas mujeres se les recomienda requerir los servicios de una obstetrix, para que les aplique ungüentos en los genitales con movimientos circulares a fin de permitir la expulsión de la materia nociva. Estas, por asi llamarlas, masturbaciones controladas, son aconsejadas por médicos tan importantes como Arnaldo de Vilanova y Johannes de Gaddesden.

- En el siglo XII, la supuesta "impureza ritual" de la mujer, entra en la Ley de la Iglesia través del Decretum Gratiani (1140), la cual se convierte en ley oficial de la Iglesia en el año 1234, siendo una parte vital del Corpus Iuris Canonici (Código Canónico), que tuvo vigencia hasta 1916, en el cual se especifica que las mujeres durante su período no pueden recibir la comunión, y si lo hacen es sobre una "toalla de eucaristia”, o en la lengua. No pueden entrar en la iglesia; no pueden bautizar; no pueden tocar los objetos sagrados; no pueden llevar puestas vestimentas sagradas; no pueden ser ordenadas y no pueden cantar en la iglesia.

- Durante el imperio de los incas (siglo XIII al siglo XVI), la primera menstruación se festeja en una ceremonia llamada quicochico, y, en ella, el hermano de la madre, al que dicen casa, cumple con el rol más destacado.

- En el siglo XIII, Pedro Hispano, en su obra el Thesaurus Pauperum (Tesoro de los Pobres), recoge una receta anticonceptiva de la medicina popular, la que contiene bajo el epígrafe "De Impedimento Conceptus", como comerse una abeja o un corazón de ciervo, pasar por encima de la sangre menstrual de otra mujer o untarse con ella.

En Thesaurus Pauperum, también se recomienda para las hemorragias genitales de las mujeres colocar en la boca de la matriz estiércol de cabra y cabezas de puerros bien machacados, así como hacer un emplasto con ranas muy bien calcinadas, mezcladas con pelos de liebre, estiércol de ésta, caldo de cabeza de vaca bien cocida y gusanos de la tierra.

En Europa, se cree ampliamente que la sangre menstrual impide germinar los cereales y agria los jugos, hace que el hierro sea atacado por el moho, que los objetos de bronce se ennegrezcan y, además, tiene la propiedad de disolver la cola de betún. La proximidad de la reglante hace que se estropeé la masa del pan, que no se ligue la pasta de buñuelos y rosquillas, 
que crezca el hollin en las calderas, que se marchiten las flores y que huyan las abejas de las colmenas. Además, es convencimiento general que los enfermos empeoran si se les acerca una mujer reglante.

En España, se cree que la mujer durante la regla es capaz de provocar con sus ojos acciones maléficas por infección; en Argamasilla de Alba y otros pueblos castellanos, es habitual pensar que si una menstruante mira o toca a un niño, le produce "mal de ojo".

- Santo Tomás de Aquino (1225-127, mira como falta el uso del matrimonio durante la menstruación, por cuanto esa circunstancia grave expone al peligro de engendrar hijos leprosos o monstruosos.

- A finales del siglo XIII e inicios del XIV, el tratado De Secretis Mulierum (Secretos de las Mujeres), la creencia en el carácter tóxico de la sangre menstrual es lo que lleva a su autor a aconsejar a los hombres que no mantengan relaciones sexuales con mujeres que tienen el periodo. En este mismo tratado, el autor aconseja sobre la acumulación de la sangre menstrual en la matriz de las jovencitas, que se deje libre a las mujeres para se acuesten con quien quieran: También en el Tratado se menciona que: "Y en ese caso es perjudicial acostarse con ellas, porque los niños que sean concebidos en ese momento tienen tendencia a desarollar epilepsia y lepra, porque dicha materia (la sangre menstrual) es extremadamente venenosa".
En otro pasaje, el autor advierte que realizar el acto sexual con mujeres menstruantes, conlleva el riesgo de contraer lepra. Además, dice que la mirada de una mujer puede empañar e incluso teñir de color sangre los espejos: "Si una mujer tiene flujo menstrual y durante ese tiempo se mira en un espejo, en dicho espejo aparece como una nube de color de sangre. Y si el espejo es nuevo, dificilmente se podrá limpiar del espejo ese enrojecimiento".

- La Escuela Montpellier del siglo XIV, explica en el tratado anónimo Tractatus de Sterilitate sobre la retención de los menstruos: "Si causa la esterilidad la sofocación de la matriz, procédase como sigue. Primero hay que saber que esta afección se produce de dos modos: por retención de los menstruos o por supresión del esperma femenino. Si la causa es por retención de los menstruos, provóquesele como hemos dichos antes [si se debe a causa cálida, como ocurre en el caso de la sangre o de la cólera, hay que sangrarla primero en la vena hepática y después resuélvanse y púrguense los humores con una decocción de flores de violeta, borrajas y ciruelas...]. Se dice que esta afección sobreviene sobre todo a viudas y doncellas. Asi pues, la mujer que padezca sofocación de la matriz, cualquiera que sea la causa de la que provenga, utilice este lectuario: cinamomo, cardamomo, macis ana tres, dracmas, pimienta larga, jengibre ana cuatro dracmas, comino, clavo, azafrán ana dos dracmas, 
espliego, ámbar gris, agácolo ana una drama, musgo o supositorio de azucena, grasa de pato, semillas de ortiga ana cuatro dracmas. Con estos ingredientes hágase una mecha e introdúzcase".

- La cultura azteca (1325-1520) cree que para renovar la "vida" del sol, las mujeres han de ofrecerle su sangre menstrual (y la sangre del parto).

A mediados de siglo XIV, la menstruación se vuelve un tema usual en los procesos inquisitoriales: "Una mujer de Lucerna confiesa haber dado a su marido su sangre menstrual como poción amorosa, pero cuando él murió poco después, ella rehusó creer que su magia fuera la causa de su muerte”.

- En 1491, El Compendio de la Humana Salud o Fasciculus Medicinae de Johannes de Ketham, se menciona los casos en los que la mujer tenga algún desarreglo en su emisión, dichos humores corrompidos degeneran en un veneno superpotente, causante de graves trastornos, e incluso de su propia muerte. $\mathrm{Y}$, ¿qué ocurre cuando la mujer llega a la menopausia? Será entonces cuando al desaparecer sus emisiones mensuales, dicha materia queda encerrada en el organismo, contaminando todo su cuerpo, pudiendo incluso envenenar a los que la rodean.

También se menciona que los hijos engendrados durante el período menstrual nacen con las más graves enfermedades de la época: lepra, varicela y sarampión. Las relaciones sexuales en el período menstrual son muy riesgosas por la impureza de la sangre y porque puede nacer un feto dañado.

Por último, Ketham menciona que el problema es en los periodos de embarazo o lactancia, ella puede tener mayores deseos sexuales en virtud del incremento de su calor corporal por la retención de la menstruación y el desbordamiento de su imaginación por el recuerdo de los placeres pasados.

- Durante el Renacimiento (siglos XIV al XVI), los bonzos (monjes budistas) de oriente aseguran que la menstruación es una señal de la ira celestial.

- Los inquisidores de fines de la edad media, Heinrich Kramer y Jaume Sprenger, en su obra Malleus Maleficarum, mencionan que las mujeres menstruantes por su propia fisonomía son más aptas para los pactos con el diablo, encantamientos y maleficios. Este planteamiento se mantiene hasta el siglo XVI.

- El médico Bernardo de Gordonio menciona que "cuando una mujer que no ha dado nunca a luz se le retira el flujo menstrual y no puede encontrar este camino para salir afuera, le sobreviene una enfermedad; algunas mujeres cuando tienen una cantidad abundante de flujo menstrual retenido en su matriz durante dos meses, llega éste al pulmón después de la retención y sufren todos aquellos sintomas descritos en el caso de la tisis, no siendo capaces de sobrevivir. Al cabo de tres meses ésta mejorará 
si logra eliminar el flujo menstrual antes retenido. Si no es así, le ocurriría lo siguiente: sufrirá sofocos de vez en cuando e igualmente tendrá fiebre, temblores y dolor en la región lumbar".

\section{CONCLUSIONES}

Desde el comienzo de los tiempos, la menstruación ha tenido un halo de misterio para la humanidad. No hay explicaciones satisfactorias aún hoy, del por qué las mujeres requieren este evento fisiológico para mantener la fertilidad, no necesario en otras especies de animales mamíferos.

El tabú de la sangre menstrual era algo muy difundido en casi todas las civilizaciones y desde tiempos remotos. Había innumerables ritos y cere- monias alrededor de los días de regla, severas restricciones y gran cantidad de leyendas sobre los efectos perniciosos que produce en los hombres y en el entorno de la mujer.

Entre los numerosas creencias sobre la menstruación durante la Edad Media, los más frecuentes son prohibir a la mujer asistir a ceremonias religiosas, mantener relaciones sexuales y preparar alimentos (sobre todo para su pareja); advertir al hombre sobre las consecuencias de tener relaciones sexuales con una mujer menstruante; lo que la mujer no puede tocar; residuo procedente de los alimentos que es necesario expulsar; que la sangre menstrual es un líquido peligroso o venenoso que puede ser utilizado como filtro amoroso y los que le confieren a la regla poderes mágicos. 